\title{
Application of iPSC to Modelling of Respiratory Diseases
}

\author{
Ben A. Calvert and Amy L. Ryan (Firth)
}

\begin{abstract}
Respiratory disease is one of the leading causes of morbidity and mortality world-wide with an increasing incidence as the aged population prevails. Many lung diseases are treated for symptomatic relief, with no cure available, indicating a critical need for novel therapeutic strategies. Such advances are hampered by a lack of understanding of how human lung pathologies initiate and progress. Research on human lung disease relies on the isolation of primary cells from explanted lungs or the use of immortalized cells, both are limited in their capacity to represent the genomic
\end{abstract}

The original version of this chapter was revised: This chapter was previously published non-open access which has now been changed to open access under a CC BY 4.0 license and the copyright holder updated to 'The Author(s)'. The correction to this chapter is available at https://doi.org/ 10.1007/978-3-030-37845-5_442

\section{B. A. Calvert}

Hastings Center for Pulmonary Research, Division of Pulmonary, Critical Care and Sleep Medicine, Department of Medicine, University of Southern California, Los Angeles, CA, USA

\section{A. L. Ryan (Firth) $(\bowtie)$}

Hastings Center for Pulmonary Research, Division of Pulmonary, Critical Care and Sleep Medicine, Department of Medicine, University of Southern California, Los Angeles, CA, USA

Department of Stem Cell Biology and Regenerative Medicine, University of Southern California,

Los Angeles, CA, USA

e-mail: amy.firth@med.usc.edu and phenotypic variability among the population. In an era where we are progressing toward precision medicine the use of patient specific induced pluripotent cells (iPSC) to generate models, where sufficient primary cells and tissues are scarce, has increased our capacity to understand human lung pathophysiology. Directed differentiation of iPSC toward lung presented the initial challenge to overcome in generating iPSC-derived lung epithelial cells. Since then major advances have been made in defining protocols to specify and isolate specific lung lineages, with the generation of airway spheroids and multi cellular organoids now possible. This technological advance has opened up our capacity for human lung research and prospects for autologous cell therapy. This chapter will focus on the application of iPSC to studying human lung disease.

\section{Keywords}

Differentiation · Human models · iPSC · Lung disease $\cdot$ NKX2.1 Stem cell

\section{Abbreviations}

ADA-SCID adenosine deaminase deficiencyrelated severe combined immunodeficiency anteriorization of the ventral foregut endoderm

ALI air-liquid interface 


\begin{tabular}{|c|c|c|}
\hline APS & & anterior primitive streak \\
\hline BMP & & bone morphogenetic protein \\
\hline CDX2 & & caudal type homeobox 2 \\
\hline $\mathrm{CF}$ & & cystic fibrosis \\
\hline CFTR & & $\begin{array}{l}\text { cystic fibrosis transmembrane } \\
\text { regulator }\end{array}$ \\
\hline COPD & & $\begin{array}{l}\text { chronic obstructive pulmonary } \\
\text { disease }\end{array}$ \\
\hline CXCR4 & & C-X-C chemokine receptor type 4 \\
\hline $\mathrm{DE}$ & & definitive endoderm \\
\hline DMD & & Duchenne's Muscular Dystrophy \\
\hline DMH-1 & & dorsomorphin homolog 1 \\
\hline ESC & & embryonic stem cells \\
\hline FACS & & flow activated cell sorting \\
\hline FGF-2 & & fibroblast growth factor 2 \\
\hline FOXA2 & & forkhead box A2 \\
\hline GATA & & GATA binding protein \\
\hline GD & & Gaucher disease \\
\hline HBEC & & human bronchial epithelial cells \\
\hline HD & & Huntington disease \\
\hline IPF & & idiopathic pulmonary fibrosis \\
\hline iPSC & & induced pluripotent stem cells \\
\hline ITGA6 & or & integrin alpha 6 \\
\hline CD49f & & \\
\hline JDM & & $\begin{array}{l}\text { juvenile-onset, type } 1 \text { diabetes } \\
\text { mellitus }\end{array}$ \\
\hline
\end{tabular}

KLF4

KRT5

LP mRNAs

NGFR

OCT4/

POU5F1

PAX6

PAX8

PCD

PD

PDX1

RA

RNA

SBDS

Shh

SOX2

SPC

TEER

TGF $\beta$

TP63
TTF1

Wnt

thyroid transcription factor 1

wingless INP pathway

\section{Introduction}

Respiratory disease is currently the third leading cause of morbidity and mortality worldwide (Lozano et al. 2012). It is also the leading cause of hospitalisations in developed countries (Hubbard 2006), placing huge individual and socioeconomic burdens on healthcare systems. Respiratory diseases encompass a wide range of disorders extending from more common diseases such as chronic obstructive pulmonary disease (COPD) and asthma to rare genetic disorders including cystic fibrosis (CF) and primary ciliary dyskinesia (PCD). Whilst each individual respiratory disorder possesses its own aetiology and pathophysiology, they often share many disease relevant commonalities, such as abnormal inflammation, increased susceptibility to infection and dysfunctional or damaged epithelia. Currently, many respiratory diseases are symptomatically managed with no effective treatment. Our understanding of disease initiation and progression is hindered through lack of robust in vitro models that closely reflect the disease phenotype as it occurs in humans for investigative research and drug screening. Many therapeutic "hits" discovered in mouse models do not translate successfully into humans leading to a high failure rate of lung therapeutics in clinical trials (Barnes et al. 2015). In this review, we evaluate the use of induced pluripotent stem cells (iPSC) for respiratory research and their potential for therapeutic applications in respiratory disease.

\section{$2 \quad$ Induced Pluripotency}

The discovery that fully differentiated/mature somatic cells can have pluripotency induced by Yamanaka et al. in 2006, ushered in a new era of genetic and cell biology research (Takahashi and Yamanaka 2006). This work identified that a minimal cocktail of 4 transcription factors, Oct4, Sox2, Klf4 and c-Myc, in combination with specific culture conditions was sufficient to 
reprogram terminally differentiated cells back into a state of pluripotency, akin to that of embryonic stem cells (ESCs) found in the inner cell mass of the blastocyst (Takahashi et al. 2007a, b; Okita et al. 2007) (Fig. 1). These cells acquired an infinite capacity for self-replication and differentiation into cells and tissues from all germ layers, including endodermal lung progenitors. As iPSC are generated by isolating cells from somatic tissues, they circumnavigate the ethical issues surrounding the use of ESCs (Murugan 2009). iPSC have revolutionized our capacity to carry out research in relevant human cells providing an exceptional tool for disease modelling, as well as possessing a huge potential for regenerative therapy.
Yamanaka and colleagues originally generated iPSC by transducing mouse fibroblasts with Oct4, Sox2, Klf4 and c-Myc transcription factors via pMX based retroviral vectors. Since then, other methods and factors have been utilized to successfully induce pluripotency in a wide range of somatic and germ line cells, these are summarized in Table 1. Initially, lentivirus became favoured over retroviruses due to its capability of infecting post-mitotic cells as well as dividing cells (Yamashita and Emerman 2006). Other virus types are also used, such as adenovirus and Sendai virus, favoured for their non-integrating nature (Zhou and Freed 2009), helping to maintain host genomic integrity with the original viral RNA diluted with each cell division (Fusaki et al. 2009). The most recent shift in technology is

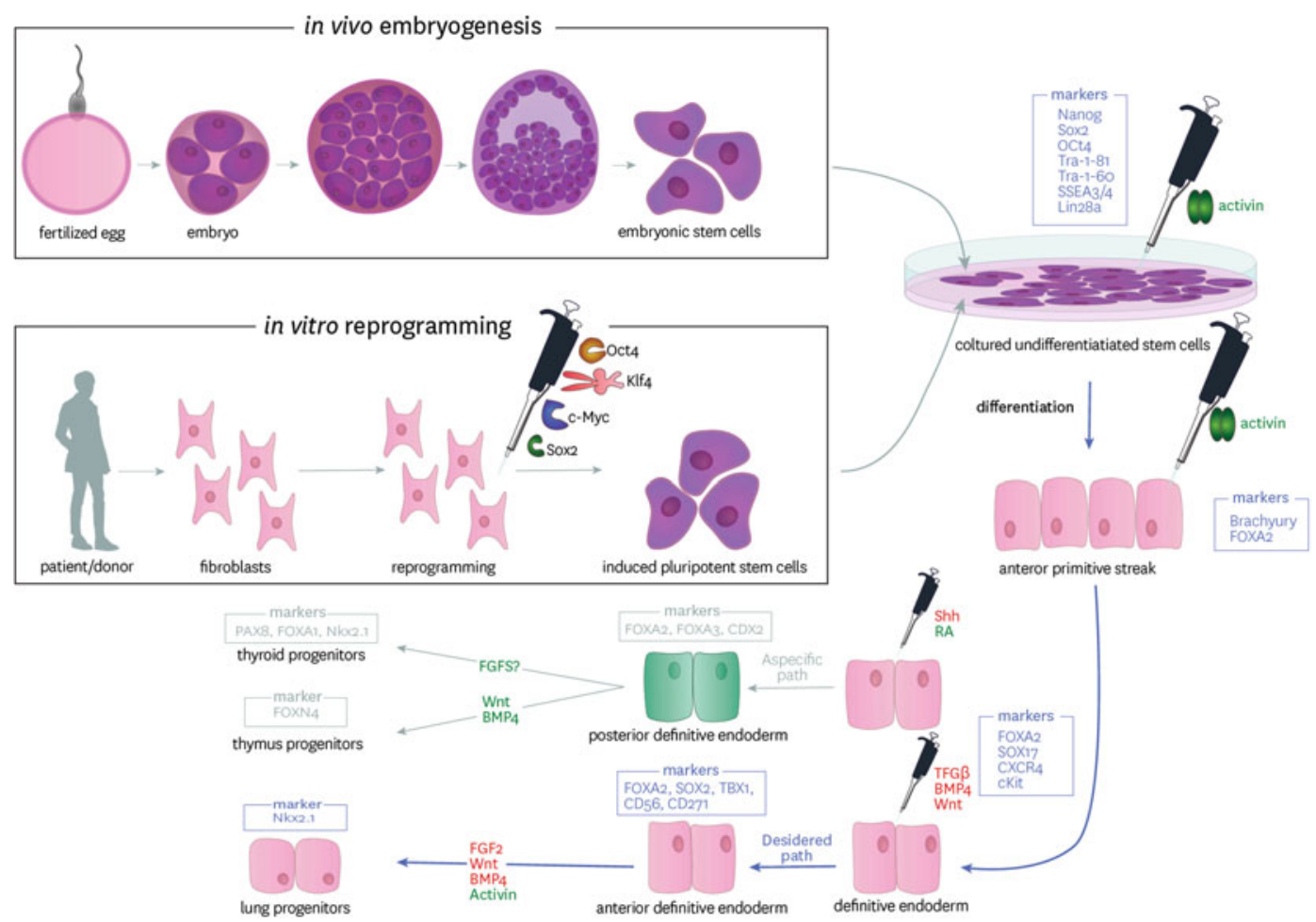

Fig. 1 Pluripotent cell differentiation toward primordial lung progenitor cells. Pluripotent stem cells are isolated and expanded in vitro from the inner cell mass of the blastocyst (Embryonic Stem Cells or ESC) or from reprogramming of somatic cells from individuals (induced pluripotent stem cells or iPSC). Following a stepwize differentiation protocol mimicking the key steps in embryogenesis, cells are differentiated through FOXA2,
SOX17 expressing definitive endoderm to anterior foregut endoderm and then NKX2.1 expressing primordial lung progenitors. The pipette symbol inidcates the cytokines and growth factors applied at each stage. The boxed genes represent key genes expressed at each stage. The red text indicates signalling that must be repressed and green text that must be activated 
Table 1 Methods for reprogramming somatic cells to iPSC

\begin{tabular}{|c|c|c|c|c|c|}
\hline Method & Vector & $\begin{array}{l}\text { Genomic } \\
\text { integration }\end{array}$ & Advantages & Disadvantages & References \\
\hline Viral & $\begin{array}{l}\text { Lentivirus, } \\
\text { retrovirus }\end{array}$ & Integrating & $\begin{array}{l}\text { High efficiency } \\
\text { stable } \\
\text { expression can } \\
\text { be inducible }\end{array}$ & $\begin{array}{l}\text { Tendency for } \\
\text { insertional } \\
\text { mutagenesis }\end{array}$ & $\begin{array}{l}\text { (Takahashi et al. (2007b), Yu et al. } \\
\text { (2007), Ohnuki et al. (2014), Carey } \\
\text { et al. (2009), Hotta et al. (2009), } \\
\text { Sommer et al. (2009) and Liao et al. } \\
\text { (2008) }\end{array}$ \\
\hline \multirow[t]{2}{*}{ Viral } & \multirow{2}{*}{$\begin{array}{l}\text { Sendai, } \\
\text { adenovirus }\end{array}$} & \multirow{2}{*}{$\begin{array}{l}\text { Non- } \\
\text { integrating }\end{array}$} & High efficiency & \multirow{2}{*}{$\begin{array}{l}\text { Tendency to carry } \\
\text { host genome }\end{array}$} & \multirow{2}{*}{$\begin{array}{l}\text { Zhou and Freed (2009), Fusaki et al. } \\
\text { (2009), Fujie et al. (2014) and Suzuki } \\
\text { et al. (2008) }\end{array}$} \\
\hline & & & $\begin{array}{l}\text { Non- } \\
\text { integrating }\end{array}$ & & \\
\hline \multirow{2}{*}{$\begin{array}{l}\text { Non- } \\
\text { viral }\end{array}$} & \multirow{2}{*}{$\begin{array}{l}\text { Episomal } \\
\text { vectors }\end{array}$} & \multirow{2}{*}{$\begin{array}{l}\text { Non- } \\
\text { integrating }\end{array}$} & Virus free & \multirow[t]{2}{*}{ Lower efficiency } & \multirow{2}{*}{$\begin{array}{l}\text { Okita et al. (2011), Yu et al. (2009) and } \\
\text { Hu and Slukvin (2013) }\end{array}$} \\
\hline & & & $\begin{array}{l}\text { Single } \\
\text { transfection }\end{array}$ & & \\
\hline \multirow[t]{2}{*}{$\begin{array}{l}\text { Non- } \\
\text { viral }\end{array}$} & \multirow[t]{2}{*}{$\begin{array}{l}\text { PiggyBac } \\
\text { transposon }\end{array}$} & \multirow[t]{2}{*}{$\begin{array}{l}\text { Non- } \\
\text { integrating }\end{array}$} & \multirow[t]{2}{*}{$\begin{array}{l}\text { Evidence for } \\
\text { more rapid } \\
\text { reprogramming }\end{array}$} & $\begin{array}{l}\text { Labour intensive } \\
\text { and relatively low } \\
\text { efficiency }\end{array}$ & \multirow[t]{2}{*}{$\begin{array}{l}\text { Yusa et al. (2009) and Stadtfeld and } \\
\text { Hochedlinger (2009) }\end{array}$} \\
\hline & & & & $\begin{array}{l}\text { Inefficient } \\
\text { excision }\end{array}$ & \\
\hline $\begin{array}{l}\text { Non- } \\
\text { viral }\end{array}$ & $\begin{array}{l}\text { Mini-circle } \\
\text { vectors }\end{array}$ & $\begin{array}{l}\text { Non- } \\
\text { integrating }\end{array}$ & $\begin{array}{l}\text { Virus free. } \\
\text { Higher } \\
\text { efficiency of } \\
\text { transfection }\end{array}$ & $\begin{array}{l}\text { Longer ectopic } \\
\text { expression }\end{array}$ & $\begin{array}{l}\text { Narsinh et al. (2011) and Jia et al. } \\
(2010)\end{array}$ \\
\hline \multirow{2}{*}{$\begin{array}{l}\text { Non- } \\
\text { viral }\end{array}$} & \multirow[t]{2}{*}{ Plasmid } & \multirow{2}{*}{$\begin{array}{l}\text { Non- } \\
\text { integrating }\end{array}$} & \multirow[t]{2}{*}{ Virus free } & Low efficiency & \multirow{2}{*}{$\begin{array}{l}\text { Kim et al. (2016), Dowey et al. (2012), } \\
\text { Karow et al. (2011), Si-Tayeb et al. } \\
\text { (2010) and Okita et al. (2010) }\end{array}$} \\
\hline & & & & $\begin{array}{l}\text { Multiple rounds } \\
\text { of transfection }\end{array}$ & \\
\hline $\begin{array}{l}\text { Non- } \\
\text { viral }\end{array}$ & Protein & $\begin{array}{l}\text { Non- } \\
\text { integrating }\end{array}$ & $\begin{array}{l}\text { No genetic } \\
\text { material, direct } \\
\text { protein delivery }\end{array}$ & $\begin{array}{l}\text { Very slow } \\
\text { reprogramming } \\
\text { kinetics, very low } \\
\text { efficiency }\end{array}$ & $\begin{array}{l}\text { Tammam et al. (2016), Nemes et al. } \\
\text { (2014), Thier et al. (2012) and Thier } \\
\text { et al. (2010) }\end{array}$ \\
\hline
\end{tabular}

toward the use of non-viral methods of reprogramming including mRNAs (Warren et al. 2010), episomal plasmids (Okita et al. 2008), recombinant proteins (Zhou et al. 2009; Kim et al. 2009) using the four original Yamanaka factors. Other transcription factors have also found to be useful in the generation of iPSC. Many of these relate to the superfamilies of the transcription factors identified by Yamanaka, such as Oct3, Sox1 and Klf2 (Yu et al. 2007).

\section{3 iPSC and Their Capacity for Disease Modelling}

iPSCs have evolved rapidly as a technology, enabling the effective modelling of human disease, complimenting the more typical approaches using animal models and immortalised cell lines. Each model system has its own benefits and limitations (summarized in Table 2). While animal models of lung disease have substantially contributed to our knowledge of fundamental lung biology there has been little success in the translation of findings into the clinic for human use (Ma et al. 2018). Animal model studies of human diseases are often limited in the pathogenic aspects of the disease that they accurately recapitulate; for example, bleomycin instillation of animal models is often used to generate in vivo models of idiopathic pulmonary fibrosis, however does not accurately represent the onset or propagation of the disease. While informing us of some aspects, these models do not always replicate the complete aetiology and pathogenesis of the disease being studied. Primary isolated human cells are difficult to expand in culture without losing their phenotype with passage (Schiller and Bittner 1995). Further, human tissue availability can be limited and most often acquired post-mortem. 
Table 2 Possible iPSC derived models for lung disease

\begin{tabular}{l|l|l|l|l|l}
\hline Model & Species & Model usage & Benefits & Limitations & References \\
\hline Organoid & Human & $\begin{array}{l}\text { Lung structural } \\
\text { development }\end{array}$ & $\begin{array}{l}\text { Multiple cell types, spatially } \\
\text { organized 3D system }\end{array}$ & $\begin{array}{l}\text { Unsuitable for } \\
\text { specific pathway } \\
\text { analysis. No air } \\
\text { interface }\end{array}$ & $\begin{array}{l}\text { Dye et al. (2015), } \\
\text { Wilkinson et al. (2018) } \\
\text { and Chen et al. (2017) }\end{array}$ \\
\hline $\begin{array}{l}\text { Air liquid } \\
\text { Interface }\end{array}$ & $\begin{array}{l}\text { Human } \\
\text { mouse }\end{array}$ & $\begin{array}{l}\text { Epithelial } \\
\text { barrier } \\
\text { formation and } \\
\text { function }\end{array}$ & $\begin{array}{l}\text { Physiologically relevant air } \\
\text { interfacing system, high } \\
\text { throughput potential, TEER } \\
\text { measurement }\end{array}$ & $\begin{array}{l}\text { No presence of } \\
\text { mesenchymal } \\
\text { niche cells }\end{array}$ & $\begin{array}{l}\text { Firth et al. (2014), Wong } \\
\text { et al. (2012) and } \\
\text { Hawkins et al. (2017) }\end{array}$ \\
\hline Transplant & $\begin{array}{l}\text { Human } \\
\text { mouse }\end{array}$ & $\begin{array}{l}\text { Cell } \\
\text { engraftment } \\
\text { and in vivo } \\
\text { regeneration }\end{array}$ & $\begin{array}{l}\text { Study engraftment potential } \\
\text { of cell-based therapy, In } \\
\text { vivo niche }\end{array}$ & $\begin{array}{l}\text { Long-term } \\
\text { human studies } \\
\text { lacking, immune } \\
\text { suppression }\end{array}$ & $\begin{array}{l}\text { Shafa et al. (2018) and } \\
\text { Okuyama et al. (2019) }\end{array}$ \\
\hline Spheroid & $\begin{array}{l}\text { Human } \\
\text { mouse }\end{array}$ & $\begin{array}{l}\text { Cellular and } \\
\text { structural } \\
\text { modelling, } \\
\text { functional } \\
\text { assays }\end{array}$ & $\begin{array}{l}\text { Suitable for stringent } \\
\text { pathway analysis, functional } \\
\text { swelling }\end{array}$ & $\begin{array}{l}\text { No air interface, } \\
\text { usually lacks } \\
\text { niche cells }\end{array}$ & $\begin{array}{l}\text { Konishi et al. (2016), } \\
\text { Gotoh et al. (2014), Dye } \\
\text { et al. (2015) and Jacob } \\
\text { et al. (2017) }\end{array}$ \\
\hline
\end{tabular}

TEER Trans Epithelial Electrical Resistance

This leads to a finite number of cells available for research from a limited patient population, which can result in limited use in high-throughput and drug screening research. Also, research into primary post-mitotic cells, such as that of neurones (Frade and Ovejero-Benito 2015), are restricted to the number of cells that can be initially isolated. This also limits the study of disease propagation and onset to what is typically an advanced disease state.

iPSCs provide an alternative and complimentary research tool that can overcome several limitations of animal models, primary and immortalized human cells. Restrictions of using primary and immortalized cell lines are surmounted due to their indefinite clonal expansion when maintained under specific culture conditions with the capacity for differentiation into multiple cell types comprising the human body (Kogut et al. 2014; Firth et al. 2015; Menon et al. 2015; Ward and Gilad 2019; Hnatiuk and Mercola 2019; Meijer et al. 2019; Fyfe 2019; Fiorotto et al. 2019; Hoshina et al. 2018; Mucci et al. 2018; Tan et al. 2018) including cells within the respiratory system. iPSC, therefore, have the potential to provide a seemingly unlimited source of patient/disease specific cells. This opens up multiple new options for research and the prospect for autologous cell therapy (Ebert et al. 2012). This chapter will focus on their application to studying human lung disease.

Genetic disorders are a prime example of where iPSC benefit over conventional in vitro disease modelling. Genetic diseases are often rare and have multiple subtypes, such as those seen in CF (Marson et al. 2016). Whilst the specific mutations of these subtypes are documented, access to patient specific material is limited, severely hindering studies of disease pathology. Instead, self-renewing iPSC can have the genetic mutation induced via state of the art gene editing technology, such as clustered regularly interspaced palindromic repeat (CRISPR)/Cas9 (Qi et al. 2013; Haurwitz et al. 2010; Wang et al. 2013; Cong et al. 2013). A concerted effort over the past decade has seen the evolution of protocols to differentiate iPSC to cells of the respiratory epithelium (Firth et al. 2014; Wong et al. 2012; Green et al. 2011; Cheng et al. 2012; Hawkins et al. 2017). This technology now enables rare genetic disorders to be modelled in a relevant and human cellular system. Several disease states have successfully been induced in iPSC including adenosine deaminase deficiencyrelated severe combined immunodeficiency (ADA-SCID), Shwachman-Bodian-Diamond syndrome (SBDS), Gaucher disease (GD) type III, Duchenne's Muscular Dystrophy (DMD), 
Parkinson disease (PD), Huntington disease (HD), juvenile-onset, type 1 diabetes mellitus (JDM) (Park et al. 2008). The concept here is to develop an iPSC line and induce a disease phenotype in the cells by knocking out/in certain genes, or challenging the cells with factors that may onset disease. The field of neuroscience has particularly benefited from the use of iPSC (Wang and Doering 2012), as obtaining primary neuronal tissue is particularly challenging. Such diseases include Alzheimer's disease (Kondo et al. 2013), Huntington's disease (Kaye and Finkbeiner 2013) and schizophrenia (Brennand et al. 2011). The connexion to this paradigm is that iPSC derived from patient populations with rare genetic disorders, can be gene corrected through use of the same gene editing technology. While providing isogenic controls for in vitro evaluation this additionally opens up the potential for autologous cell based therapies reducing the need for immunosuppression and the likelihood of tissue rejection. In the respiratory field, proofof-principle studies have demonstrated the correction of cystic fibrosis transmembrane regulator (CFTR) in CF patient derived iPSC, which were subsequently differentiated into functional epithelial cells (Firth et al. 2015; Crane et al. 2015). Providing a basis for novel iPSC based therapies for $\mathrm{CF}$ patients in the future.

\section{$4 \quad$ Specification of Primordial Lung Progenitors from iPSC}

Directed differentiation of iPSC toward lung endoderm presents its own set of challenges, which the field has made substantial progress toward elucidating over the past decade (Firth et al. 2014; Hannan et al. 2015; Wong and Rossant 2013). The lungs are a sophisticated organ system comprising of complex structures and over 40 different cell types; they include a complex vasculature, sympathetic and parasympathetic neuronal innovation, structural support and a specialized respiratory epithelium. To add to this complexity, the structure of the airways changes to meet its functional requirements along the proximal-distal axis. Similar to the gut, the respiratory system also contains a natural homeostatic microbiota, which can drastically alter during times of disease and stress (Dang and Marsland 2019; Man et al. 2017) and is an internal organ exposed to the exterior environment increasing the potential for epigenetic modification (Sakurada 2010; Hagood 2014). These features must all be considered when creating an in vitro model of respiratory disease and reflected in the advantages and limitations of any given model system. iPSC have the potential to investigate mechanisms of human lung development providing insights into the differentiation pathways from stem cell to fully differentiated tissues. In addition, they provide an opportunity to reverse a disease phenotype and investigate mechanisms of disease onset.

The first methods describing directed differentiation of the respiratory epithelium from iPSC focused primarily on specification of the lung endoderm (Cheng et al. 2012; Kadzik and Morrisey 2012; Longmire et al. 2012a). Subsequently, three pioneering papers were published differentiating cells to more mature cells in the respiratory epithelium (Wong et al. 2012; Kadzik and Morrisey 2012; Firth et al. 2014). These studies all strived to mimic lung embryonic development in a dish pushing cells through mesendoderm, to definitive endoderm (DE) followed by anteriorization of the ventral foregut endoderm (AFE) to primordial NKX2.1 expressing lung endodermal progenitor cells (LP). These cells have the capacity for differentiation into cells akin to that for the mature human lung including club, goblet, multiciliated, basal, alveolar and neuroendocrine cells.

Understanding lung development is critical to efficiently driving pluripotent cells to generate the cells and structures comprising the human lung. There is still a sparsity of specific knowledge of human lung development and much of our information is gained from transgenic mouse models tracing lineage specification (Bellusci et al. 1997a, b; Weaver et al. 1999, 2003; Okubo and Hogan 2004; Rawlins et al. 2009a, b). Lung organogenesis begins in the embryonic period with independent outpouchings of the ventral wall in the primitive foregut endoderm that 
elongate and branch into the surrounding mesenchyme. The respiratory mesenchyme is crucial in many developmental and homeostatic processes within the lung. It provides key signalling ligands to promote the development of lung structures, including alveolargenesis, airway branching and the vasculature. The mesenchyme is the primary source of transforming growth factor beta (TGF $\beta$ ) in the developing lung (McCulley et al. 2015; White et al. 2006). It is an integral component for natural development and TGF $\beta$ knockout studies demonstrate impaired lung development (Sanford et al. 1997). The mesenchyme also provides the primary source of Wnt signalling, key for branching morphogenesis of airway epithelium (Miller et al. 2012) (Fig. 1).

DE gives rise to lungs, thyroid, pancreas, liver and intestines and is specified from the anterior primitive streak (APS), induced from pluripotent cells through strong activation of nodal and canonical wnt signaling, which are synergistically activated during gastrulation. This is mimicked in culture using Activin A and Wnt3a or Wnt agonist CHIR99021 (Kubo et al. 2004). The APS can be pushed to DE through persistent activation of nodal signalling and inhibition of bone morphogenetic protein (BMP), using DMH-1, to suppress mesoderm derivation (Green et al. 2011; Ogaki et al. 2013). Specification of DE from the mesendoderm has been optimized and results in a high efficiency of DE cells from iPSC (Mfopou et al. 2010). In embryonic development Wnt signalling plays an important role in many cellular functions, including differentiation and proliferation, in Vitro Wnt3A signalling is used to skew away from SOX2 expressing ectoderm and promote endodermal differentiation. DE also expresses cell surfaces markers CXCR4, a chemokine receptor important in cellular proliferation and cKit that can purify the DE through FACS sorting (Wong et al. 2010; Wang et al. 2012) (Fig. 2).

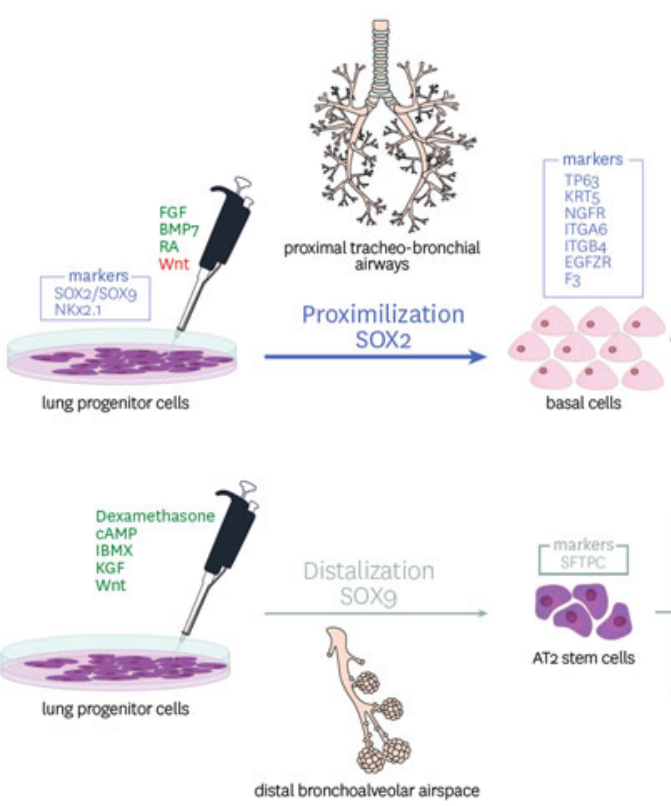

Fig. 2 Differentiation of primordial lung progenitors towards proximal and distal lung fate. iPSC derived and purified lung progenitor cells expressing $\mathrm{NKx} 2.1$ can be directed toward proximal and distal fates through activation (green) and inhibition (red) of signalling pathways including those driven by FGFs, BMPs and wnts. The markers of the specific lineages are indicated in boxes

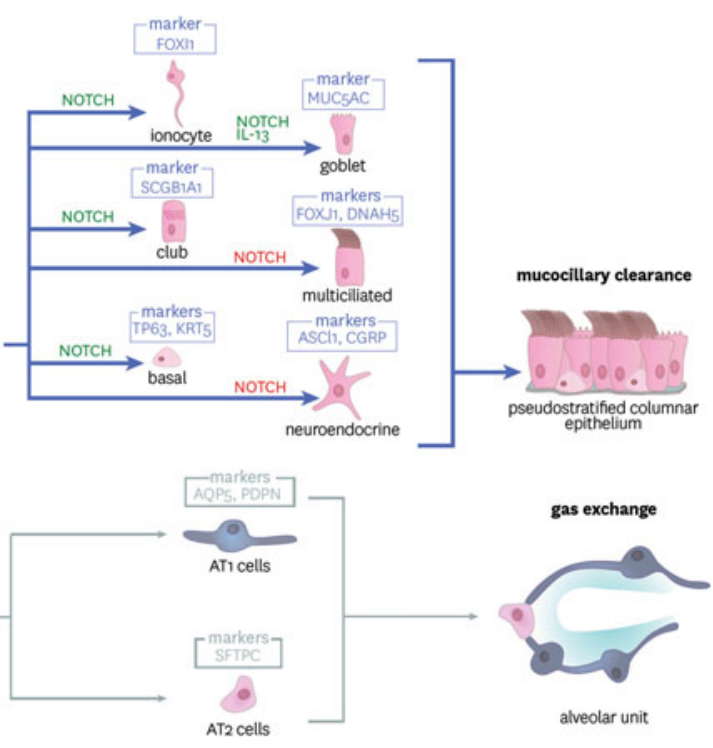

above the cell types. Alveolar Type II (ATII) cells are the progenitor cells giving rise to mature ATII and ATI cells responsive for the functional alveolar unit for gas exchange. Sox 2 expressing proximal basal cells are able to differentiate and give rise to all cells of the mature conducting airways including secretory, basal and multiciliated cells responsible for mucociliary clearance 
Anterioriziation of the DE to generate the foregut, identified through SOX2 and FOXA2 expressing cells does not appear to critically depend on Activin A/TGF- $\beta$-signalling. Inhibition of TGF $\beta$ is known to assist in driving AFE (Green et al. 2011) and an inhibition of Wnt- and BMP-signalling is critical in optimizing this transition. FOXA2 is an essential transcription factor for lung development, FOXA2-/- mice do not develop lungs (Wan et al. 2004; Aubin et al. 1997). Retinoic acid (RA), commonly used in lung differentiation protocols has dual effects and can either posteriorize or dorsalize the foregut creating PDX1-positive pancreatic duodenal cells. Its use in in vitro differentiation protocols is, therefore, not entirely clear. A number of studies have demonstrated the importance of RA, influencing micro RNAs, however, short pulses of RA can also maintain the stemness of iPSC through inhibition of the canonical Wnt pathway, essential for differentiation (De Angelis et al. 2018). In combination with $\mathrm{Wnt} / \beta$-catenin, RA can act synergistically with FGF-2 and BMP-4 to generate CDX2-positive posterior endoderm further complicating the methods applied to iPSC differentiation (Davenport et al. 2016).

The successful generation of a primordial lung progenitor cell is accredited to the induction of lung transcription factor NKX2.1 (also known as TTF1) (Longmire et al. 2012a; Lazzaro et al. 1991). The function of NKX2.1 is not entirely understood. In mouse models, it is important in the development of respiratory tissue as well as other thoracic structures (Minoo et al. 1999; Minoo 2000). Purification of iPSC derived NKX2.1 primordial lung progenitor cells initially proved inefficient and purification was limited through lack of a suitable surface antigen. A recent study has shown that these NKX2.1 cells can be selected using a CD47high, CD26-low surface marker expression profile (Hawkins et al. 2017). Alternatively, Carboxypeptidase $\mathrm{M}$ is also expressed in these cells and can be used to purify a similar population of lung progenitors (Konishi et al. 2016; Gotoh et al. 2014). While NKX2.1 defines specification of lung progenitor cells, it also has notable expression in the brain and thyroid tissues (Lee et al. 2001; Rossi et al. 1995; Acebron et al. 1995). Although the pathways that distinguish between these organ systems are not well-characterised, lineages can be identified though co-expression of PAX8 (thyroid, (Rossi et al. 1995) and PAX6 (forebrain, (Corbin et al. 2003; Takahashi and Osumi 2002).

Fibroblast Growth Factor (FGF) signalling is integral in defining lung endoderm and inducing NKX2.1 expression (Rankin and Zorn 2014; Dailey et al. 2005; Xian et al. 2005). In addition, sonic hedgehog (Shh) and transcriptional programs of the forkhead (Fox), and GATAfamily members, are involved in specification of the lung from the AFE (Hogan 1999; Whitsett 1998). Differentiation towards lung progenitors can be directed away from specification of thyroid progenitors through controlled FGF2 expression. Studies have demonstrated that high concentrations of FGF activate Shh expression to generate NKX2-1 expressing lung progenitors and thyroid (Rankin and Zorn 2014; Serra et al. 2017; Kurmann et al. 2015; Longmire et al. 2012b). Dye et al. demonstrated that suppression of FGF activity whilst maintaining Shh signalling allowed for a more specific differentiation to lung primed NKX2.1 expressing cells (Dye et al. 2015). Sequential inhibition of TGF $\beta$ signalling, followed by subsequent activation of FGF and BMP4 signalling pathways can support further differentiation to lung epithelium (Longmire et al. 2012a).

\section{$5 \quad$ Proximal and Distal Fate of Lung Progenitors}

Lung buds arise from the lateral part of the foregut prior to forming the trachea and recent data suggests that the progenitors at the leading tip of these lung buds differ in humans and mice and can specify both the proximal and distal regions of the lung (Miller et al. 2018; Danopoulos et al. 2018; Nikolic et al. 2017). To study these fate decisions in humans a three-dimensional organoid system has been established to culture fetal lung bud tips (Miller et al. 2018; Danopoulos 
et al. 2018; Nikolic et al. 2017). Cells at the leading tip of these buds express NKx2.1, SOX2 and SOX9 in humans; this contrasts with the cells in the same region of the mouse which either co-express NKX2.1 and SOX2 or SOX9 (Miller et al. 2018). A similar population of cells has been observed in iPSC derived lung progenitors from humans (Miller et al. 2018).

Detailed analysis of the regulation of proximal and distal fate decisions has been extensively studied in mice using lineage tracing models (Rawlins et al. 2009b; Barkauskas et al. 2013; Rock et al. 2009). In humans, we rely on the development of robust in vitro models. Both fetal and iPSC derived lung bud organoids will differentiate when exposed to FGF7, CHIR and Retinoic Acid, generating cells akin to those in the human airways (Miller et al. 2018). By utilizing more sophisticated scaffold materials, tubular airway-like structures can also be replicated in vitro, resembling that of the canalicular development in lung embryogenesis (Dye et al. 2016). Additional factors to consider when developing more complex models, is the importance of the mesenchymal supporting cells in controlling the fate of lung progenitors towards a proximal or distal epithelial phenotypes. Signals between the mesenchyme and epithelium are critical in lung development, and supplying the exogenous growth factors to an in vitro system may be in sufficient to allow us to fully appreciate the signals responsible for proximal and distal human lung fate decisions (El Agha et al. 2014).

\section{Tracheo-Bronchial Differentiation and Disease Models}

Specification of distal and proximal lung cells requires precise spatiotemporal regulation of Wnt, Notch and FGF signaling pathways. The proximal airways, comprising of tracheal and bronchial cartilaginous airways, are populated by basal cells, as the predominant progenitor cell, in addition to club and goblet secretory cells and multiciliated cells as the primary functional epithelium. SOX2 expression delineates the proximal airways from their distal counterparts that continue to selectively express SOX9 (Danopoulos et al. 2018). As discussed above, bud tip progenitors co-express both SOX2 and SOX9 during psuedoglandular phase of human embryogenetic development, however, will become determined before development reaches the canalicular stages, controlled by signals received within their proximity microenvironment (Danopoulos et al. 2018).

Currently there are no published studies specifically focusing on the specification and expansion of an iPSC-derived basal cell. Proximal airway basal cells are currently identified by the expression of cytokeratin 5 (KRT5), TP63, nerve growth factor receptor (NGFR) and integrin alpha 6 (ITGA6 or CD49f) (Daniely et al. 2004). During development, it appears that SMAD signaling plays a role in the lineage differentiation pushing away from lung progenitor stem cells. TGF $\beta$ and BMP4 mediated SMAD signaling has, however, been demonstrated to promote the differentiation from bud tips to a basal cell like phenotype, using an organoid based in vitro system (Dye et al. 2015). At this stage, SMAD inhibition promotes the maintenance of the basal cell phenotype and further differentiation beyond a precursor cell (Mou et al. 2016).

Another key component for differentiation to lung basal cell epithelium is NOTCH signaling (Rock et al. 2011). Activation of Notch signaling pathways is critical in embryonic development and plays various roles in a more developed system. In the basal cell, NOTCH signaling is involved in its further differentiation to a mature epithelial subtype. Maturation of airways cells is most commonly achieved at an "air-liquid interface" or ALI, a platform arguably more complex than in vitro systems for most other organ systems (de Jong et al. 1994). In this system, human bronchial epithelial cells (HBEC) are seeded to transwell inserts, allowed to grow to confluence generating an epithelial barrier with tight junctions. Once sufficient trans-epithelial electrical resistance (TEER) is generated, the apical media is removed generating an apical air interface. Over a 28-day period the cells undergo process of polarization, pseudo stratification and 
maturation comprising predominantly of basal, secretory (goblet and club cells) and multiciliated cells. Inhibition of NOTCH promotes a basal cell to ciliated cell transition, whist continued activation of NOTCH pathways promote a secretory fate (Rock et al. 2011). Successful differentiation of ALI cultures from iPSC was demonstrated in some of the first protocols published (Wong and Rossant 2013; Firth et al. 2014). Since than several other laboratories have generated pseudostratified epithelium reflecting that of the primary airway cell differentiation in vitro (Konishi et al. 2016; McCauley et al. 2017; Huang et al. 2015).

\section{Distal Lung and Alveolar Differentiation and Disease Models}

Cells expressing NKX2-1 stand as the distinct lung progenitor that may differentiate into any lung cellular phenotype. Lung patterning during embryogenesis requires determination to distinguish the saccular generation of the distal alveolar spaces. In vitro generation of more distally aligned airway cells can be controlled via Wnt signalling. It had been demonstrated that high Wnt activation could generate alveolar progenitors whilst conversely supressed Wnt signalling generated more proximal cell types (McCauley et al. 2017). This is primarily achieved by culturing the cells in the presence of a potent GSK3 $\beta$ inhibitor known as CHIR99021. Inhibiting the ability of this enzyme to activate Wnt and its downstream machinery. The result is the robust generation of distal/alveolar epithelial cells (Jacob et al. 2017).

Alveolar epithelium is comprised of two major subtypes; alveolar type 1 (AT1) \& alveolar type 2 (AT2) cells. In short, AT1 cells provide the structural basis of the alveolar spaces and primary function for gaseous exchange, whilst AT2 cells are primarily secretory and provide a supporting role to the AT1 cells. However, there is distinct multifunctional heterogeneity within these cell types. This was eloquently demonstrated utilising a surfactant protein C (SPC) (AT2 specific marker) reporter line, whereby phenotypic profiling multiple subtypes within this specific cell population (Lee et al. 2013). Interestingly, mutations in SPC are known to cause interstitial lung disease, and have been modelled utilising iPSC derived AT2 cells (Jacob et al. 2017). The AT2 cells derived from iPSCs are found to be NKX2.1 and closely resemble that of the foetal lung AT2 cells, based on a genetic profiling. This model is now being utilised to study the influence of $173 \mathrm{~T}$ SPC mutation and effectively model interstitial lung disease in vitro. Other distally aligned respiratory diseases have also been modelled in vitro utilising iPSC-based techniques. These include IPF models where 3-D organoids have been able to replicate disease characteristics including accumulation of extracellular matrix and mesenchymal cells, suggesting the potential for modelling fibrotic lung disease in vitro (Wilkinson et al. 2017; Strikoudis et al. 2019).

The development of lung progenitor cells is limited by our understanding of the phenotype and function of their primary counterpart. To date no direct comparison has been made between iPSC-derived cells and in vitro cultured primary cells. With substantial profiling of cells in progress through programs such as LungMAP (https://lungmap.net), it is hoped that a more extensive profile of basal cells and potential sub populations of progenitor cells will lead to increased options of specific cellular surface markers for specific identification and isolation of the definitive stem cells.

\section{8 iPSC and their Capacity for Tissue Regeneration}

Many degenerative disorders, such as COPD, do not have effective disease modifying treatments. In theory, iPSC could be generated from each patient diseases, differentiated to the relevant stem/progenitor cell and engrafted back into the patient's diseased and damaged lung. Furthermore, genetic disorders, such $\mathrm{CF}$ and primary ciliary dyskinesia, could be corrected using state-of-the-art gene editing technologies prior to 
engraftment. Published data has demonstrated the successful use of iPSC-derived cells and their regenerative therapeutic potential in a multitude of disorders using animal models and in vitro based techniques. These include models of liver injury (Liu et al. 2011), muscular related disorders (Kazuki et al. 2010; Tan et al. 2012), blood/immunological disorders (Suzuki et al. 2013), cardiovascular disease (Shiba et al. 2016) and spinal cord injury (Nori et al. 2011), among others (Li et al. 2017). In the clinic, patient specific, iPSC-derived retinal epithelial cells have successfully been transplanted back into patients with macular degeneration, marking the first attempt of iPSC to treat a patient population (Mandai et al. 2017). Unfortunately, the reality of this is infinitely more challenging and complex for the lung. The lung comprises of over 40 different functional cell types forming airways, vasculature, cartilage, immune system, sympathetic and parasympathetic neural tissues, glands and supportive parenchyma. In the case of lung disease, it unlikely that one cell type is affected in isolation and more reasonable to think of changes more globally with specific microenvironments adapting to maximize protection and function of the lung for gas exchange. Long-term replacement of cells will likely require access to the relevant cellular niche for long-term reconstitution and adaptation of the niche to reflect that of a non-diseased lung to sustain a "healthy" engrafted cell and derivatives. Progress in the field of lung regeneration has been substantial but we now need to start thinking toward more complex models, which more closely recapitulate the in vivo cellular niche. This will require, at minimum, collaborative efforts between biologists, bioengineers and novel translational imaging techniques.

\section{The Future of iPSC for Respiratory Disease}

iPSC present a novel, human and patient specific avenue for research and therapeutic advancement. iPSC have enabled the generation of human and disease-related models to be created in vitro providing an unprecedented access to human biology. Like any model system, they are not without their limitations and should be used alongside other available systems suitable for completely addressing the specific experimental question at hand. For the lung, exposure of the cells to the environment, a constant for the millieu of cells in the airways, is not yet considered in this model system. Furthermore, epigenetic changes causative of disease are likely wiped during the reprogramming process loosing these markers as disease phenotypes. However, by utilising iPSC, a seemingly limitless source of cells is available and representative of the parent genetic profile enabling both human and patient specific cellular models to be developed. Further, the use of iPSC allows for robust investigations into the developmental pathways involved in a human cell-based system that would otherwise be challenging. In iPSC, individual genes can be manipulated and evaluated side-by-side with their isogenic counterparts enabling precise effects of specific genes to be evaluated. As such, iPSC provide an incredibly valuable model system as we progress to an era of personalized medicine.

\section{Concluding Remarks}

Substantial progress has been made since Yamanaka's discovery of induced pluripotency in humans in 2007. From initially identifying an iPSC inducing minimal cocktail of transcription factors, to sucessful use of iPSC as a therapeutic tool, highlights the speed at which this technlogy has evolved. Although initial derivation of relevant respiratory cells from iPSC lagged behing other organ systems, we still have a plethora of methods available to study respiratory disease in a biologically relevant cell type, overcoming the shortfall of current model systems. Progress is currently limited by our fundamental lack of understanding of the mechanisms controlling human lung development, the precise identity and function of human lung cell types and the genetic and epigenetic control of human lung fate. As our capacity to model human lung disease 
evolves, so will our understanding of the pathogenesis of human lung disease. iPSC models remain an exciting prospect.

Acknowledgements Thank you to Sergio Bianco in the USC Department of Stem Cell and Regenerative Medicine for production of the artwork for the schematic diagrams in figures 1 and 2 .

Funding A.L.R. is funded by the Hastings Foundation, Cystic Fibrosis Foundation Therapeutics (CFFT, Firth15XX0, Firth17XX0) and NIH/NHLBI, R01 HL139828.

\section{References}

Acebron A, Aza-Blanc P, Rossi DL, Lamas L, Santisteban $\mathrm{P}$ (1995) Congenital human thyroglobulin defect due to low expression of the thyroid-specific transcription factor TTF-1. J Clin Invest 96(2):781-785

Aubin J, Lemieux M, Tremblay M, Berard J, Jeannotte L (1997) Early postnatal lethality in Hoxa-5 mutant mice is attributable to respiratory tract defects. Dev Biol 192 (2):432-445

Barkauskas CE et al (2013) Type 2 alveolar cells are stem cells in adult lung. J Clin Invest 123(7):3025-3036

Barnes PJ et al (2015) Barriers to new drug development in respiratory disease. Eur Respir J 45(5):1197-1207

Bellusci S et al (1997a) Involvement of Sonic hedgehog (Shh) in mouse embryonic lung growth and morphogenesis. Development 124(1):53-63

Bellusci S, Grindley J, Emoto H, Itoh N, Hogan BL (1997b) Fibroblast growth factor 10 (FGF10) and branching morphogenesis in the embryonic mouse lung. Development 124(23):4867-4878

Brennand KJ et al (2011) Modelling schizophrenia using human induced pluripotent stem cells. Nature 473 (7346):221-225

Carey BW et al (2009) Reprogramming of murine and human somatic cells using a single polycistronic vector. Proc Natl Acad Sci U S A 106(1):157-162

Chen YW et al (2017) A three-dimensional model of human lung development and disease from pluripotent stem cells. Nat Cell Biol 19(5):542-549

Cheng X et al (2012) Self-renewing endodermal progenitor lines generated from human pluripotent stem cells. Cell Stem Cell 10(4):371-384

Cong L et al (2013) Multiplex genome engineering using CRISPR/Cas systems. Science (New York, NY) 339 (6121):819-823

Corbin JG, Rutlin M, Gaiano N, Fishell G (2003) Combinatorial function of the homeodomain proteins $\mathrm{Nkx} 2.1$ and Gsh2 in ventral telencephalic patterning. Development 130(20):4895-4906
Crane AM et al (2015) Targeted correction and restored function of the CFTR gene in cystic fibrosis induced pluripotent stem cells. Stem Cell Rep 4(4):569-577

Dailey L, Ambrosetti D, Mansukhani A, Basilico C (2005) Mechanisms underlying differential responses to FGF signaling. Cytokine Growth Factor Rev 16 (2):233-247

Dang AT, Marsland BJ (2019) Microbes, metabolites, and the gut-lung axis. Mucosal Immunol 12(4):843-850

Daniely Y et al (2004) Critical role of p63 in the development of a normal esophageal and tracheobronchial epithelium. Am J Phys Cell Physiol 287(1):C171C181

Danopoulos S et al (2018) Human lung branching morphogenesis is orchestrated by the spatiotemporal distribution of ACTA2, SOX2, and SOX9. Am J Physiol Lung Cell Mol Physiol 314(1):L144-L149

Davenport C, Diekmann U, Budde I, Detering N, Naujok O (2016) Anterior-posterior patterning of definitive endoderm generated from human embryonic stem cells depends on the differential signaling of retinoic acid, Wnt-, and BMP-signaling. Stem Cells 34 (11):2635-2647

De Angelis MT, Parrotta EI, Santamaria G, Cuda G (2018) Short-term retinoic acid treatment sustains pluripotency and suppresses differentiation of human induced pluripotent stem cells. Cell Death Dis 9(1):6

de Jong PM et al (1994) Ciliogenesis in human bronchial epithelial cells cultured at the air-liquid interface. Am J Respir Cell Mol Biol 10(3):271-277

Dowey SN, Huang X, Chou BK, Ye Z, Cheng L (2012) Generation of integration-free human induced pluripotent stem cells from postnatal blood mononuclear cells by plasmid vector expression. Nat Protoc 7 (11):2013-2021

Dye BR et al (2015) In vitro generation of human pluripotent stem cell derived lung organoids. elife 4:e05098

Dye BR et al (2016) A bioengineered niche promotes in vivo engraftment and maturation of pluripotent stem cell derived human lung organoids. elife 5:pii: e19732

Ebert AD, Liang P, Wu JC (2012) Induced pluripotent stem cells as a disease modeling and drug screening platform. J Cardiovasc Pharmacol 60(4):408-416

El Agha E et al (2014) Fgf10-positive cells represent a progenitor cell population during lung development and postnatally. Development 141(2):296-306

Fiorotto R et al (2019) Liver diseases in the dish: iPSC and organoids as a new approach to modeling liver diseases. Biochim Biophys Acta Mol basis Dis 1865 (5):920-928

Firth AL et al (2014) Generation of multiciliated cells in functional airway epithelia from human induced pluripotent stem cells. Proc Natl Acad Sci U S A 111(17): E1723-E1730

Firth AL et al (2015) Functional gene correction for cystic fibrosis in lung epithelial cells generated from patient iPSCs. Cell Rep 12(9):1385-1390 
Frade JM, Ovejero-Benito MC (2015) Neuronal cell cycle: the neuron itself and its circumstances. Cell Cycle 14 (5):712-720

Fujie Y et al (2014) New type of Sendai virus vector provides transgene-free iPS cells derived from chimpanzee blood. PLoS One 9(12):e113052

Fusaki N, Ban H, Nishiyama A, Saeki K, Hasegawa M (2009) Efficient induction of transgene-free human pluripotent stem cells using a vector based on Sendai virus, an RNA virus that does not integrate into the host genome. Proc Jpn Acad Ser B Phys Biol Sci 85 (8):348-362

Fyfe I (2019) Mutation-specific amyloid-beta processing in iPSC-derived neurons. Nat Rev Neurol 15(6):310

Gotoh S et al (2014) Generation of alveolar epithelial spheroids via isolated progenitor cells from human pluripotent stem cells. Stem Cell Rep 3(3):394-403

Green MD et al (2011) Generation of anterior foregut endoderm from human embryonic and induced pluripotent stem cells. Nat Biotechnol 29(3):267-272

Hagood JS (2014) Beyond the genome: epigenetic mechanisms in lung remodeling. Physiology (Bethesda) 29(3):177-185

Hannan NR, Sampaziotis F, Segeritz CP, Hanley NA, Vallier L (2015) Generation of distal airway epithelium from multipotent human foregut stem cells. Stem Cells Dev 24(14):1680-1690

Haurwitz RE, Jinek M, Wiedenheft B, Zhou K, Doudna JA (2010) Sequence- and structure-specific RNA processing by a CRISPR endonuclease. Science (New York, NY) 329(5997):1355-1358

Hawkins F et al (2017) Prospective isolation of NKX2-1expressing human lung progenitors derived from pluripotent stem cells. J Clin Invest 127(6):2277-2294

Hnatiuk A, Mercola M (2019) Stars in the night sky: iPSCcardiomyocytes return the patient context to drug screening. Cell Stem Cell 24(4):506-507

Hogan BL (1999) Morphogenesis. Cell 96(2):225-233

Hoshina A et al (2018) Development of new method to enrich human iPSC-derived renal progenitors using cell surface markers. Sci Rep 8(1):6375

Hotta A et al (2009) Isolation of human iPS cells using EOS lentiviral vectors to select for pluripotency. Nat Methods 6(5):370-376

Hu K, Slukvin I (2013) Generation of transgene-free iPSC lines from human normal and neoplastic blood cells using episomal vectors. Methods Mol Biol 997:163-176

Huang SX et al (2015) The in vitro generation of lung and airway progenitor cells from human pluripotent stem cells. Nat Protoc 10(3):413-425

Hubbard R (2006) The burden of lung disease. Thorax 61 (7):557-558

Jacob A et al (2017) Differentiation of human pluripotent stem cells into functional lung alveolar epithelial cells. Cell Stem Cell 21(4):472-488. e410
Jia F et al (2010) A nonviral minicircle vector for deriving human iPS cells. Nat Methods 7(3):197-199

Kadzik RS, Morrisey EE (2012) Directing lung endoderm differentiation in pluripotent stem cells. Cell Stem Cell 10(4):355-361

Karow M et al (2011) Site-specific recombinase strategy to create induced pluripotent stem cells efficiently with plasmid DNA. Stem Cells 29(11):1696-1704

Kaye JA, Finkbeiner S (2013) Modeling Huntington's disease with induced pluripotent stem cells. Mol Cell Neurosci 56:50-64

Kazuki Y et al (2010) Complete genetic correction of iPS cells from Duchenne muscular dystrophy. Mol Ther 18 (2):386-393

Kim D et al (2009) Generation of human induced pluripotent stem cells by direct delivery of reprogramming proteins. Cell Stem Cell 4(6):472-476

Kim JS, Choi HW, Hong YJ, Do JT (2016) Generation of partially reprogrammed cells and fully reprogrammed iPS cells by plasmid transfection. Methods Mol Biol 1357:85-95

Kogut I, Roop DR, Bilousova G (2014) Differentiation of human induced pluripotent stem cells into a keratinocyte lineage. Methods Mol Biol 1195:1-12

Kondo T et al (2013) Modeling Alzheimer's disease with iPSCs reveals stress phenotypes associated with intracellular Abeta and differential drug responsiveness. Cell Stem Cell 12(4):487-496

Konishi $S$ et al (2016) Directed induction of functional multi-ciliated cells in proximal airway epithelial spheroids from human pluripotent stem cells. Stem Cell Rep 6(1):18-25

Kubo A et al (2004) Development of definitive endoderm from embryonic stem cells in culture. Development 131(7):1651-1662

Kurmann AA et al (2015) Regeneration of thyroid function by transplantation of differentiated pluripotent stem cells. Cell Stem Cell 17(5):527-542

Lazzaro D, Price M, de Felice M, Di Lauro R (1991) The transcription factor TTF-1 is expressed at the onset of thyroid and lung morphogenesis and in restricted regions of the foetal brain. Development 113 (4): 1093-1104

Lee BJ et al (2001) TTF-1, a homeodomain gene required for diencephalic morphogenesis, is postnatally expressed in the neuroendocrine brain in a developmentally regulated and cell-specific fashion. Mol Cell Neurosci 17(1):107-126

Lee JH et al (2013) Surfactant protein-C chromatin-bound green fluorescence protein reporter mice reveal heterogeneity of surfactant protein C-expressing lung cells. Am J Respir Cell Mol Biol 48(3):288-298

Li Y-C, Zhu K, Young T-H (2017) Induced pluripotent stem cells, form in vitro tissue engineering to in vivo allogeneic transplantation. J Thorac Dis 9(3):455-459 
Liao J et al (2008) Enhanced efficiency of generating induced pluripotent stem (iPS) cells from human somatic cells by a combination of six transcription factors. Cell Res 18(5):600-603

Liu H, Kim Y, Sharkis S, Marchionni L, Jang Y-Y (2011) In vivo liver regeneration potential of human induced pluripotent stem cells from diverse origins. Sci Transl Med 3(82):82ra39-82ra39

Longmire TA et al (2012a) Efficient derivation of purified lung and thyroid progenitors from embryonic stem cells. Cell Stem Cell 10(4):398-411

Longmire TA, Ikonomou L, Kotton DN (2012b) Mouse ESC differentiation to $\mathrm{Nkx} 2.1+$ lung and thyroid progenitors. Bio Protoc 2(22):pii: e295

Lozano R et al (2012) Global and regional mortality from 235 causes of death for 20 age groups in 1990 and 2010: a systematic analysis for the global burden of disease study 2010. Lancet (London, England) 380 (9859):2095-2128

Ma Q et al (2018) Regeneration of functional alveoli by adult human SOX9(+) airway basal cell transplantation. Protein Cell 9(3):267-282

Man WH, de Steenhuijsen Piters WA, Bogaert D (2017) The microbiota of the respiratory tract: gatekeeper to respiratory health. Nat Rev Microbiol 15 (5):259-270

Mandai M et al (2017) Autologous induced stem-cellderived retinal cells for macular degeneration. $\mathrm{N}$ Engl J Med 376(11):1038-1046

Marson FAL, Bertuzzo CS, Ribeiro JD (2016) Classification of CFTR mutation classes. Lancet Respir Med 4 (8):e37-e38

McCauley KB et al (2017) Efficient derivation of functional human airway epithelium from pluripotent stem cells via temporal regulation of Wnt signaling. Cell Stem Cell 20(6):844-857. e846

McCulley D, Wienhold M, Sun X (2015) The pulmonary mesenchyme directs lung development. Curr Opin Genet Dev 32:98-105

Meijer M et al (2019) A single-cell model for synaptic transmission and plasticity in human iPSC-derived neurons. Cell Rep 27(7):2199-2211. e2196

Menon $\mathrm{T}$ et al (2015) Lymphoid regeneration from genecorrected SCID-X1 subject-derived iPSCs. Cell Stem Cell 16(4):367-372

Mfopou JK, Chen B, Sui L, Sermon K, Bouwens L (2010) Recent advances and prospects in the differentiation of pancreatic cells from human embryonic stem cells. Diabetes 59(9):2094-2101

Miller MF et al (2012) Wnt ligands signal in a cooperative manner to promote foregut organogenesis. Proc Natl Acad Sci U S A 109(38):15348-15353

Miller AJ et al (2018) In vitro induction and in vivo engraftment of lung bud tip progenitor cells derived from human pluripotent stem cells. Stem Cell Rep 10 (1):101-119
Minoo P (2000) Transcriptional regulation of lung development: emergence of specificity. Respir Res 1 (2):109-115

Minoo P, Su G, Drum H, Bringas P, Kimura S (1999) Defects in tracheoesophageal and lung morphogenesis in Nkx2.1(-/-) mouse embryos. Dev Biol 209 (1):60-71

Mou $\mathrm{H}$ et al (2016) Dual SMAD signaling inhibition enables long-term expansion of diverse epithelial basal cells. Cell Stem Cell 19(2):217-231

Mucci A et al (2018) iPSC-derived macrophages effectively treat pulmonary alveolar Proteinosis in Csf2rbdeficient mice. Stem Cell Rep 11(3):696-710

Murugan V (2009) Embryonic stem cell research: a decade of debate from bush to Obama. Yale J Biol Med 82 (3):101-103

Narsinh KH et al (2011) Generation of adult human induced pluripotent stem cells using nonviral minicircle DNA vectors. Nat Protoc 6(1):78-88

Nemes C et al (2014) Generation of mouse induced pluripotent stem cells by protein transduction. Tissue Eng Part C Methods 20(5):383-392

Nikolic MZ et al (2017) Human embryonic lung epithelial tips are multipotent progenitors that can be expanded in vitro as long-term self-renewing organoids. elife 6: pii: e26575

Nori S et al (2011) Grafted human-induced pluripotent stem-cell-derived neurospheres promote motor functional recovery after spinal cord injury in mice. Proc Natl Acad Sci U S A 108(40):16825-16830

Ogaki S, Shiraki N, Kume K, Kume S (2013) Wnt and Notch signals guide embryonic stem cell differentiation into the intestinal lineages. Stem Cells 31 (6): $1086-1096$

Ohnuki M et al (2014) Dynamic regulation of human endogenous retroviruses mediates factor-induced reprogramming and differentiation potential. Proc Natl Acad Sci U S A 111(34):12426-12431

Okita K, Ichisaka T, Yamanaka S (2007) Generation of germline-competent induced pluripotent stem cells. Nature 448(7151):313-317

Okita K, Nakagawa M, Hyenjong $\mathrm{H}$, Ichisaka $\mathrm{T}$, Yamanaka S (2008) Generation of mouse induced pluripotent stem cells without viral vectors. Science (New York, NY) 322(5903):949-953

Okita K, Hong H, Takahashi K, Yamanaka S (2010) Generation of mouse-induced pluripotent stem cells with plasmid vectors. Nat Protoc 5(3):418-428

Okita K et al (2011) A more efficient method to generate integration-free human iPS cells. Nat Methods 8 (5):409-412

Okubo T, Hogan BL (2004) Hyperactive Wnt signaling changes the developmental potential of embryonic lung endoderm. J Biol 3(3):11

Okuyama H et al (2019) Transplantation of multiciliated airway cells derived from human iPS cells using an 
artificial tracheal patch into rat trachea. J Tissue Eng Regen Med 13(6):1019-1030

Park IH et al (2008) Disease-specific induced pluripotent stem cells. Cell 134(5):877-886

Qi LS et al (2013) Repurposing CRISPR as an RNA-guided platform for sequence-specific control of gene expression. Cell 152(5):1173-1183

Rankin SA, Zorn AM (2014) Gene regulatory networks governing lung specification. J Cell Biochem 115 (8):1343-1350

Rawlins EL, Clark CP, Xue Y, Hogan BL (2009a) The Id2 + distal tip lung epithelium contains individual multipotent embryonic progenitor cells. Development 136(22):3741-3745

Rawlins EL et al (2009b) The role of Scgb1a1+ Clara cells in the long-term maintenance and repair of lung airway, but not alveolar, epithelium. Cell Stem Cell 4 (6):525-534

Rock JR et al (2009) Basal cells as stem cells of the mouse trachea and human airway epithelium. Proc Natl Acad Sci U S A 106(31):12771-12775

Rock JR et al (2011) Notch-dependent differentiation of adult airway basal stem cells. Cell Stem Cell 8 (6):639-648

Rossi DL, Acebron A, Santisteban P (1995) Function of the homeo and paired domain proteins TTF-1 and Pax-8 in thyroid cell proliferation. J Biol Chem 270 (39):23139-23142

Sakurada K (2010) Environmental epigenetic modifications and reprogramming-recalcitrant genes. Stem Cell Res 4(3):157-164

Sanford LP et al (1997) TGFbeta2 knockout mice have multiple developmental defects that are non-overlapping with other TGFbeta knockout phenotypes. Development 124(13):2659-2670

Schiller JH, Bittner G (1995) Loss of the tumorigenic phenotype with in vitro, but not in vivo, passaging of a novel series of human bronchial epithelial cell lines: possible role of an alpha 5/beta 1-integrin-fibronectin interaction. Cancer Res 55(24):6215-6221

Serra $M$ et al (2017) Pluripotent stem cell differentiation reveals distinct developmental pathways regulating lung- versus thyroid-lineage specification. Development 144(21):3879-3893

Shafa M et al (2018) Human induced pluripotent stem cellderived lung progenitor and alveolar epithelial cells attenuate hyperoxia-induced lung injury. Cytotherapy 20(1):108-125

Shiba Y et al (2016) Allogeneic transplantation of iPS cellderived cardiomyocytes regenerates primate hearts. Nature 538(7625):388-391

Si-Tayeb K et al (2010) Generation of human induced pluripotent stem cells by simple transient transfection of plasmid DNA encoding reprogramming factors. BMC Dev Biol 10:81

Sommer CA et al (2009) Induced pluripotent stem cell generation using a single lentiviral stem cell cassette. Stem Cells 27(3):543-549
Stadtfeld M, Hochedlinger K (2009) Without a trace? PiggyBac-ing toward pluripotency. Nat Methods 6 (5):329-330

Strikoudis A et al (2019) Modeling of fibrotic lung disease using 3D organoids derived from human pluripotent stem cells. Cell Rep 27(12):3709-3723. e3705

Suzuki K et al (2008) Highly efficient transient gene expression and gene targeting in primate embryonic stem cells with helper-dependent adenoviral vectors. Proc Natl Acad Sci U S A 105(37):13781-13786

Suzuki N et al (2013) Generation of engraftable hematopoietic stem cells from induced pluripotent stem cells by way of teratoma formation. Mol Ther 21(7):1424-1431

Takahashi M, Osumi N (2002) Pax6 regulates specification of ventral neurone subtypes in the hindbrain by establishing progenitor domains. Development 129 (6): $1327-1338$

Takahashi K, Yamanaka S (2006) Induction of pluripotent stem cells from mouse embryonic and adult fibroblast cultures by defined factors. Cell 126(4):663-676

Takahashi K, Okita K, Nakagawa M, Yamanaka S (2007a) Induction of pluripotent stem cells from fibroblast cultures. Nat Protoc 2(12):3081-3089

Takahashi K et al (2007b) Induction of pluripotent stem cells from adult human fibroblasts by defined factors. Cell 131(5):861-872

Tammam S et al (2016) Nuclear delivery of recombinant OCT4 by chitosan nanoparticles for transgene-free generation of protein-induced pluripotent stem cells. Oncotarget 7(25):37728-37739

Tan Q, Lui PP, Rui YF, Wong YM (2012) Comparison of potentials of stem cells isolated from tendon and bone marrow for musculoskeletal tissue engineering. Tissue Eng A 18(7-8):840-851

Tan YT et al (2018) Respecifying human iPSC-derived blood cells into highly engraftable hematopoietic stem and progenitor cells with a single factor. Proc Natl Acad Sci U S A 115(9):2180-2185

Thier M, Munst B, Edenhofer F (2010) Exploring refined conditions for reprogramming cells by recombinant Oct4 protein. Int J Dev Biol 54(11-12):1713-1721

Thier M, Munst B, Mielke S, Edenhofer F (2012) Cellular reprogramming employing recombinant sox 2 protein. Stem Cells Int 2012:549846

Wan $\mathrm{H}$ et al (2004) Foxa2 is required for transition to air breathing at birth. Proc Natl Acad Sci U S A 101 (40):14449-14454

Wang H, Doering LC (2012) Induced pluripotent stem cells to model and treat neurogenetic disorders. Neural Plast 2012:346053

Wang P et al (2012) A molecular signature for purified definitive endoderm guides differentiation and isolation of endoderm from mouse and human embryonic stem cells. Stem Cells Dev 21(12):2273-2287

Wang $\mathrm{H}$ et al (2013) One-step generation of mice carrying mutations in multiple genes by CRISPR/Cas-mediated genome engineering. Cell 153(4):910-918 
Ward MC, Gilad Y (2019) A generally conserved response to hypoxia in iPSC-derived cardiomyocytes from humans and chimpanzees. elife 8:pii: e42374

Warren L et al (2010) Highly efficient reprogramming to pluripotency and directed differentiation of human cells with synthetic modified mRNA. Cell Stem Cell 7(5):618-630

Weaver M, Yingling JM, Dunn NR, Bellusci S, Hogan BL (1999) Bmp signaling regulates proximal-distal differentiation of endoderm in mouse lung development. Development 126(18):4005-4015

Weaver M, Batts L, Hogan BL (2003) Tissue interactions pattern the mesenchyme of the embryonic mouse lung. Dev Biol 258(1):169-184

White AC et al (2006) FGF9 and SHH signaling coordinate lung growth and development through regulation of distinct mesenchymal domains. Development 133 (8): $1507-1517$

Whitsett J (1998) A lungful of transcription factors. Nat Genet 20(1):7-8

Wilkinson DC et al (2017) Development of a threedimensional bioengineering technology to generate lung tissue for personalized disease modeling. Stem Cells Transl Med 6(2):622-633

Wilkinson DC et al (2018) Development of a threedimensional bioengineering technology to generate lung tissue for personalized disease modeling. Curr Protoc Stem Cell Biol 46(1):e56

Wong AP, Rossant J (2013) Generation of lung epithelium from pluripotent stem cells. Curr Pathobiol Rep 1 (2):137-145
Wong JC et al (2010) Definitive endoderm derived from human embryonic stem cells highly express the integrin receptors alphaV and beta5. Cell Adhes Migr 4(1):39-45

Wong AP et al (2012) Directed differentiation of human pluripotent stem cells into mature airway epithelia expressing functional CFTR protein. Nat Biotechnol 30(9):876-882

Xian W, Schwertfeger KL, Vargo-Gogola T, Rosen JM (2005) Pleiotropic effects of FGFR1 on cell proliferation, survival, and migration in a 3D mammary epithelial cell model. J Cell Biol 171(4):663-673

Yamashita M, Emerman M (2006) Retroviral infection of non-dividing cells: old and new perspectives. Virology 344(1):88-93

$\mathrm{Yu} \mathrm{J}$ et al (2007) Induced pluripotent stem cell lines derived from human somatic cells. Science (New York, NY) 318(5858):1917-1920

$\mathrm{Yu}$ J et al (2009) Human induced pluripotent stem cells free of vector and transgene sequences. Science (New York, NY) 324(5928):797-801

Yusa K, Rad R, Takeda J, Bradley A (2009) Generation of transgene-free induced pluripotent mouse stem cells by the piggyBac transposon. Nat Methods 6 (5):363-369

Zhou W, Freed CR (2009) Adenoviral gene delivery can reprogram human fibroblasts to induced pluripotent stem cells. Stem Cells 27(11):2667-2674

Zhou $\mathrm{H}$ et al (2009) Generation of induced pluripotent stem cells using recombinant proteins. Cell Stem Cell 4(5):381-384

Open Access This chapter is licensed under the terms of the Creative Commons Attribution 4.0 International License (http://creativecommons.org/licenses/by/4.0/), which permits use, sharing, adaptation, distribution and reproduction in any medium or format, as long as you give appropriate credit to the original author(s) and the source, provide a link to the Creative Commons license and indicate if changes were made.

The images or other third party material in this chapter are included in the chapter's Creative Commons license, unless indicated otherwise in a credit line to the material. If material is not included in the chapter's Creative Commons license and your intended use is not permitted by statutory regulation or exceeds the permitted use, you will need to obtain permission directly from the copyright holder.

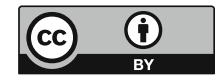

